\title{
FARKLI KALINLIKTAKİ BAZI DOĞAL TAŞLARIN KOPMA ENERJİSİ VE ÇARPMA DAYANIMININ BELİRLENMESİ
}

\author{
Ece KUNDAK ${ }^{*}{ }^{*}$,Hürriyet AKDAŞ² , Gencay SARIIŞIK ${ }^{3}$
}

${ }^{1}$ Eskişehir Osmangazi Üniversitesi, Mühendislik ve Mimarlık Fakültesi, Maden Müh. Bölümü, Batı Meşelik Yerleşkesi, 26480 Eskișehir, ORCID No : https://orcid.org/0000-0001-5491-7058

2 Eskișehir Osmangazi Üniversitesi, Mühendislik ve Mimarlık Fakültesi, Maden Müh. Bölümü, Batı Meșelik Yerleșkesi, 26480 Eskișehir, ORCID No : https://orcid.org/0000-0002-8416-1228

${ }^{3}$ Harran Üniversitesi, Mühendislik Fakültesi, Endüstri Müh. Bölümü, Osmanbey Yerleşkesi,63190 Şanlıurfa, ORCID No : https://orcid.org/0000-0002-1112-3933

\begin{tabular}{|c|c|}
\hline Anahtar Kelimeler & Öz \\
\hline $\begin{array}{l}\text { Kopma enerjisi } \\
\text { Carpma dayanımı } \\
\text { Doğal taş } \\
\text { TS EN } 14158 \\
\text { Doğal taş kalınlığı }\end{array}$ & 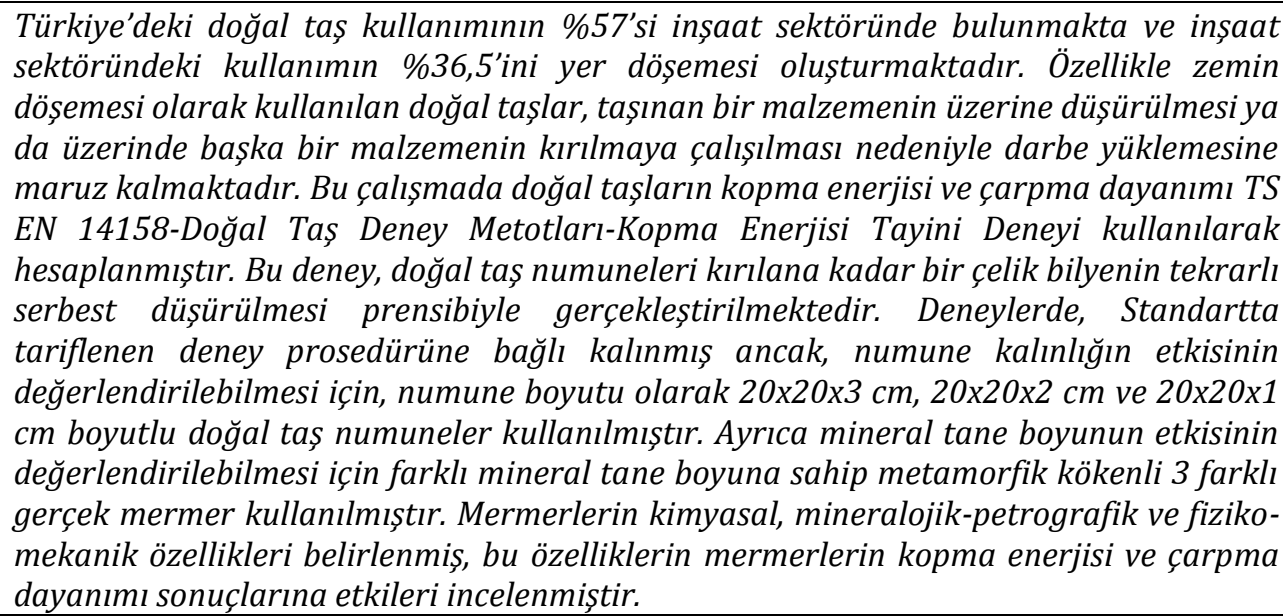 \\
\hline
\end{tabular}

\section{DETERMINATION OF RUPTURE ENERGY AND IMPACT STRENGTH OF SOME NATURAL STONES IN DIFFERENT THICKNESS}

\begin{tabular}{l}
\hline Keywords \\
\hline Rupture energy \\
Impact strength \\
Natural stone \\
EN 14158 \\
Natural stone thickness
\end{tabular}
Abstract

In Turkey, 57\% of the use of natural stone takes place in the construction sector and $36.5 \%$ of the use in the construction sector is used as flooring material. Natural stones, which are used especially as flooring, are subject to impact loading due to falling over a carried material or trying to break another material on it. In this study, the rupture energy and impact strength of natural stones were calculated by using EN 14158-Natural Stone Test Methods-Determination of Rupture Energy Experiment. This experiment is carried out on the principle of repeated free drop of a steel ball until the natural stone samples are broken. In the experiments, it was adhered to the test procedure described in the Standard, but $20 \times 20 \times 3 \mathrm{~cm}, 20 \times 20 \times 2 \mathrm{~cm}$ and $20 \times 20 \times 1 \mathrm{~cm}$ natural stone samples were used as the sample size to evaluate the effect of the sample thickness. In addition, 3 different metamorphic marbles with different mineral grain sizes were used to evaluate the effect of mineral grain size. Chemical, mineralogical-petrographic and physicomechanical properties of marbles have been determined and the effects of these properties on the results of tensile energy and impact strength of marbles have been examined.

\begin{tabular}{llll}
\hline Araştırma Makalesi & \multicolumn{3}{l}{ Research Article } \\
Başvuru Tarihi & $: 17.02 .2020$ & Submission Date & $: 17.02 .2020$ \\
Kabul Tarihi & $: 13.03 .2020$ & Accepted Date & $: 13.03 .2020$ \\
\hline
\end{tabular}

\section{Giriş}

Doğal taşlar, günümüzde doğal ürünlere verilen önemin artması, nefes alabilen doğal bir malzeme olması, sağlam ve dayanıklı olması gibi nedenlerle pek çok alanda kullanılmaktadır. Türkiye'de doğal taşların tüketim alanlarına göre tüketim yüzdeleri incelendiğinde; \%36,5 ile zemin döşemesi, \%9,5 ile iç

\footnotetext{
*Sorumlu yazar; e-posta : ecekundak@gmail.com
} 
duvar kaplaması, \%7,5 ile diş duvar kaplaması, \%3,5 ile basamaklar, \%13 ile hediyelik eşya, \%10 ile heykel, $\% 7,5$ ile mezar taşları ve \%2,5 ile diğer alanlar gelmektedir. İnşaat sektöründe döșeme, kaplama ve basamak malzemesi olarak kullanılan doğal taşlar, Türkiye doğal taş tüketiminin \%57'sini oluşturmaktadır (Onargan, Köse ve Deliormanlı, 2011).

Bir doğal taş ürünün kullanım alanı belirlenirken; öncelikle taşın kullanılacağı mekanın özelliklerinin (iç mekan ya da dış mekan; ıslak zemin ya da kuru zemin; iklim koşulları; yaya sirkülasyonu ve yoğunluğunu vb.), sonrasında doğal taşın jeolojik kökeninin, kimyasal bileşiminin, fiziko-mekanik özelliklerinin (özgül ağırlık, su emme, porozite, sertlik, basınç dayanımı, eğilme dayanımı, aşınma direnci, darbe dayanımı, don sonrası basınç dayanımı vb.) tespit edilmesi gerekir. Mekan ve doğal taş özelliklerinin belirlenmesinin ardından kullanıcı zevki ve estetik de göz önünde bulundurularak uygun doğal taş seçimi gerçekleştirilir. Doğal taşların doğru yerlerde kullanımı estetik uygunluk ve uzun ömürlülük anlamında olumlu sonuçlar verirken; yanlış yerlerde kullanımı da istenmeyen sonuçları beraberinde getirmektedir (Öztank ve Türkmen, 2001). Hatalı bir uygulama sonucunda ortaya çıkan bir işin yeniden yapılması ve/veya onarılması iki kat işçilik maliyetine, zaman ve malzeme kaybına sebep olmaktadır (Koçu ve Dereli, 2003). Bu olumsuz koşullar doğrudan yapı maliyetine yansıdığı gibi, dolaylı olarak da milli ekonomiye yansıyacaktır. $\mathrm{Bu}$ nedenle, kullanılacak ortam koşulları ve kullanım yerine göre doğal taşın kimyasal, mineralojik-petrografik ve fiziko-mekanik özellikleri göz önünde bulundurularak doğal taş seçimi yapılmalıdır.

Doğal taşlar günümüzde pek çok yapıda zemin döşemesi, duvar kaplaması, basamak ve tezgah malzemesi olarak kullanılmaktadır. Doğal taşların, özellikle zemin döşemesi ve tezgah malzemesi olarak kullanıldıklarında sıklıkla maruz kaldıkları yüklemelerden birisi de, darbe (çarpma) yüklemeleridir. Bir cismin, diğer bir cisim ile anlık ve şiddetli bir şekilde çarpışması olarak tanımlanan darbeye karşı, doğal taşların vereceği tepkinin tespit edilebilmesi mühendislik uygulamalarında beklenmedik sonuçların ortaya çıkmaması için oldukça önemlidir. Doğal taşların kullanım alanlarında maruz kaldıkları darbe yüklemeleri genellikle, ya üzerinde taşınan bir malzemenin düşürülmesi şeklinde doğrudan, ya da üzerinde bir başka malzemenin kırılmaya çalışılması şeklinde dolaylı olarak gözlemlenmektedir. Bu tür darbeler, benzer yapıda ve düşük hızda olmalarına karşın; etkileri çok değişkendir. $\mathrm{Bu}$ değişken etkiler nedeniyle, darbe yüklemesine maruz kalan doğal tașta bazen gözle görülür bir kusur oluşmazken, bazen pullanma, bazen çatlama, bazen de kırılma gözlemlenebilmektedir.
Darbe yüklemesi ile ilgili yapılan çalışmaların çoğu metaller ve kompozitler üzerinde gerçekleştirilmiştir. Düşük hızlı darbe testlerinden sarkaç testleri genellikle metal malzemelerin darbe davranışını karakterize etmekte kullanılırken; ağırlık düşürme testleri ise kompozit malzemelerin darbe davranışını karakterize etmekte kullanılmaktadır. Sarkaç testlerinin uygulanma prosedürleri standart olmasına karşın; ağırlık düşürme testleri için çok farklı uygulama prosedürleri (farklı ağırlıklı düşürücüler, farklı şekilli düşürücüler, farklı düşürme yükseklikleri, farklı numune boyutları vb.) vardır. Ağırlık düşürme testlerinde, farklı ülkelerin ve farklı kuruluşların kullandığı farklı standartlar olmakla birlikte; darbe davranışını karakterize etmek için araştırmacılar arasında yaygın bir şekilde kabul görmüş herhangi bir standart deney yöntemi mevcut değildir (Kundak, 2016).

$\mathrm{Bu}$ çalışma kapsamında, 3 farklı doğal taşın darbe davranışı yeni bir doğal taş standardı olan TS EN 14158 kodlu ve 'Doğal taşlarda kopma enerjisinin tayini' isimli standarda göre belirlenmiştir. Bu standart, düşük hızlı darbe testlerinden serbest düşme prensibine dayanan ağırlık düşürme testi ile doğal taşların kopma enerjisini belirleme esasına dayanmaktadır. Ayrıca doğal taşların bu standartta yer alan kopma enerjisi değerinin yanı sıra standartta yer almayan ancak Sarışık G. (2012) tarafından yapılan çalışmada önerilen eşitliklerle hesaplanan çarpma dayanımı değerleri de belirlenmiştir.

\section{Bilimsel Yazın Taraması}

Literatürde TS EN 14158 kodlu standart ile ilgili çok fazla sayıda çalışmaya rastlanmamıştır.

Sarışık G. (2012) yaptığı çalışmada, doğal taş nihai plakaların çarpma dayanımının belirlenmesi için bir deney yöntemi geliştirmeyi amaçlamıştır. Çalışmada, $20 \times 20 \times 2 \mathrm{~cm}, 20 \times 20 \times 3 \mathrm{~cm}$ ve $20 \times 20 \times 4 \mathrm{~cm}$ olmak üzere 3 farklı ebatta numune kullanılmak suretiyle, 8 farklı metamorfik kökenli mermerin çarpma dayanımı yeni bir yöntemle hesaplanmıştır. Deneyler, mermer numunenin ölçümün yapılacağı manuel cihazın altında bulunan kum dolu haznenin merkezine yerleştirilmesi ve $1046 \mathrm{~g}$ ağırlıklı çelik bilyenin numune merkezine düşürülmesi ile gerçekleştirilmiştir. Bilye, numune kırılana kadar aynı yükseklikten 6 kez numune merkezine düşürülmüş ve numunenin bu $6 \mathrm{kez}$ düşmede kırılmadığı durumda; bilye yüksekliği her defasında 5 'er $\mathrm{cm}$ yükseltilerek yeni yükseklikten numune kırllana kadar tekrar 6 kez düşürülmek suretiyle deneyler gerçekleştirilmiştir. Sonrasında, numunenin kırıldığı düşme yüksekliği, kullanılan bilye ağırlığı ve numunenin hacmi kullanılarak çarpma dayanımının hesaplanması önerilmiștir. Hesaplanan çarpma dayanımı değerleri üzerinden mermerler için bir kırılma potansiyeli tablosu oluşturularak çarpma 
dayanımı değerlerine göre mermerler; yüksek, orta, düşük ve çok düşük kırılma potansiyellerinde sınıflandırılmıştır.

Sarışık, Kundak, Akdaş ve Özkan (2012) yaptıkları çalışmada, doğal taş numunelerinin kopma enerjisi, çarpma dayanımı ve farklı bir cihaz ile de sıçrama katsayısı değerlerini belirlemeyi amaçlamışlardır. Bu çalışmada, 5 adet kireçtaşı, 7 adet gerçek mermer ve 5 adet traverten örneğinin kopma ve çarpma enerjisinin tayini için 20x20x2 cm, 20x20x3 cm ve 20x20x4 cm ebatlı numuneler, sıçrama katsayısının belirlenmesi için ise, 7,5x7,5x1 cm ebatlı numuneler kullanılmıștır. Kopma enerjisi ve çarpma dayanımı tespit edilirken; özelliği belirlenecek numune cihazın kum zemini ortalanacak şekilde yerleştirilmiş ve $1044 \mathrm{~g}$ ağırlıklı çelik bilye $25 \mathrm{~cm}$ yükseklikten numunenin merkezine düşürülmüştür. Bu işlem aynı yükseklikten 6 kez olmak üzere ve numune kırılmadığı takdirde yükseklik $5 \mathrm{~cm}$ arttırılarak yeni yükseklikten de $6 \mathrm{kez}$ düşürülmek üzere deneyler, numune kırılana kadar tekrar edilmiştir. Çalışma sonunda hesaplanan doğal taşların çarpma dayanımı ve sıçrama katsayısı arasında 0,90 belirlilik katsayısında pozitif yönlü ilişki tespit edilmiştir.

Sarışık, Özkan, Kundak ve Akdaş (2016) yaptıkları çalışmada, 7 adet metamorfik kökenli ve 10 adet sedimanter kökenli doğal taşın kopma enerjisi, çarpma dayanımı ve sıçrama katsayısı değerlerini hesaplamış ve bu özelliklerine göre doğal taşların kullanım alanlarını belirlemeye çalışmışlardır. Çarpma dayanımı ve kopma enerjisi belirlenirken; 20x20 cm boyutlu $2 \mathrm{~cm}, 3 \mathrm{~cm}$ ve 4 cm kalınlıklı doğal taş numuneleri kullanılırken; sıçrama katsayısı belirlenirken 7,5x7,5x1 cm boyutlu numuneler kullanılmıştır. Doğal taşların kopma enerjisi ve çarpma dayanımı TS EN 14158 kodlu standarttaki prosedüre uygun deneyler ile belirlenirken; sıçrama katsayısı, EN ISO 10545-5 kodlu standarttaki prosedüre uygun deneyler ile belirlenmiştir. Kopma enerjisi ve çarpma dayanımı belirlenirken tüm numune ebatları için $1044 \mathrm{~g}$ ağırlıklı bilye kullanılarak ve sıçrama katsayısı belirlenirken ise, $28 \mathrm{~g}$ ve $55 \mathrm{~g}$ ağırlıklı bilyeler kullanılarak deneyler gerçekleștirilmiștir. Doğal taşların mineralojik-petrografik özellikleri, kimyasal özellikleri ve fiziko-mekanik özellikleri de belirlenmiş ve bu özelliklerin kopma enerjisi, çarpma dayanımı ve sıçrama katsayısı değerlerini nasıl etkilediği hakkında yorumlar yapılmıştır. Ayrıca kopma enerjisi $3 \mathrm{Nm}$ 'den büyük olan ve sıçrama katsayısı 0,5'den büyük olan doğal taşların, iç ve dış mekanlarda zemin ve duvar kaplama malzemesi olarak kullanımının uygun olduğu ifade edilmiştir.

\section{Materyal ve Yöntem}

\subsection{Materyal}

Bu çalıșmada kapsamında yapılan deneylerde numune olarak; jeolojik oluşumuna göre metamorfik kökenli, sertliğine göre yumuşak taşlar grubunda yer alan ve kullanım şekline göre de parlatılarak kullanılan 3 farklı doğal taş kullanılmıştır. Deneylerde, Bursa/Kemalpaşa yöresine ait Kemalpaşa Beyaz (K), Muğla/Kavak yöresine ait Muğla Beyaz (M) ve Afyon/İsçehisar yöresine ait Afyon Şeker (A) ticari isimleri ile bilinen mermerler kullanılmıştır. Çalıșmada kullanılan mermerlerin genel görüntüsü Şekil 1'de verilmektedir.

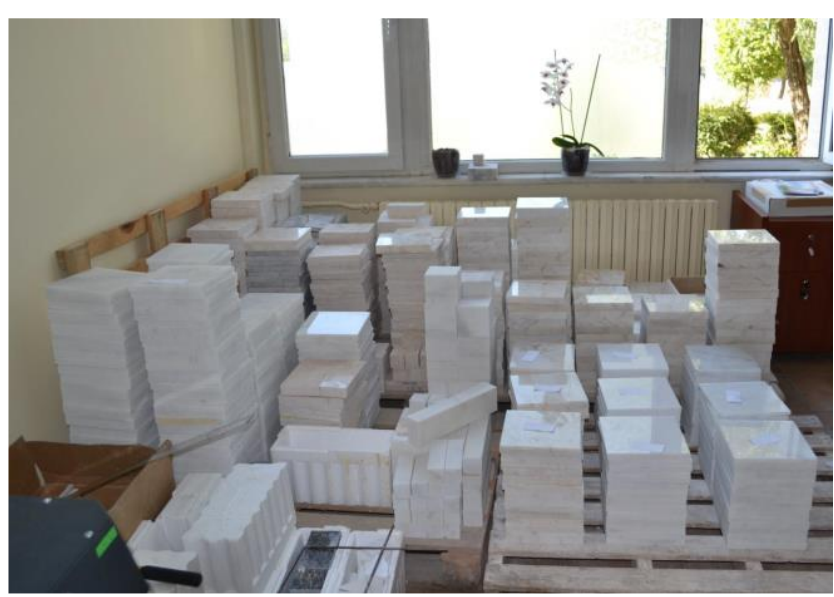

Şekil 1. Çalıșmada Kullanılan Numunelerin Genel Görüntüsü

Çalışmanın temelini oluşturan TS EN 14158 kodlu doğal taşların kopma enerjisini belirlemeye yarayan standart deney yönteminde, numunenin merkez noktasına ağırlığın serbest düşme prensibiyle tekrarlı düşürülmesiyle oluşan kırılmadan, numunenin geneli için bir kırılma enerjisi hesaplanması sağlandığından, deney yönteminin tam anlamıyla işlerliğinin ortaya konabilmesi ve deney yönteminden kaynaklı olumsuzlukların minimuma indirilebilmesi için, nispeten en az kusura sahip ve masif yapılı doğal taşlar olan Kemalpaşa Beyaz (K), Muğla Beyaz (M) ve Afyon Şeker (A)ticari isimli gerçek mermerlerin deneylerde numune olarak kullanılmasına karar verilmiştir. Bu mermerlerin benzer bir renk ve bileșimi olmasına rağmen farklı mineral tane boylarına sahip olması sebebiyle yapılan deney sonuçlarının farklı mineral tane boylarından nasıl etkilendiğinin de ortaya konması amaçlanmıștır.

Bu çalışmada araştırma ve yayın etiğine uyulmuştur.

\subsection{Tanımlama Deneyleri}

Çalışma sonunda belirlenen kopma enerjisi ve çarpma dayanımı değerlerinin yorumlanmasında deneylerde kullanılan örneklerin iyi derecede tanınması ve tanımlanması oldukça önemlidir. Bu nedenle öncelikle doğal taşların kimyasal, mineralojik-petrografik, ve fiziko-mekanik özellikleri belirlenmiştir. Çalışmada gerçekleştirilen tanımlama deneylerinin neler 
olduğu,bu özelliklerin belirlenmesinde kullanılan numunelerin yüzey özellikleri, boyutları ve sayısı Tablo 1 'de verilmiștir.

Tablo 1

Tanımlama Deneyleri

\begin{tabular}{|c|c|c|c|c|}
\hline Özellik & Deney Adı & $\begin{array}{l}\text { Numune } \\
\text { Yüzey } \\
\text { Özelliği }\end{array}$ & $\begin{array}{c}\text { Numune } \\
\text { Boyutu } \\
(\mathrm{cm})\end{array}$ & $\begin{array}{l}\text { Numune } \\
\text { Sayısı }\end{array}$ \\
\hline $\begin{array}{l}\text { Mineralojik } \\
\text { Petrografik } \\
\text { Özellikler }\end{array}$ & $\begin{array}{l}\text { İnce kesit } \\
\text { hazırlanması }\end{array}$ & ham & ince kesit & 1 adet \\
\hline $\begin{array}{l}\text { Kimyasal } \\
\text { Özellikler }\end{array}$ & $\begin{array}{l}\text { X-Işını Floresans } \\
\text { yöntemi }\end{array}$ & ham & $\begin{array}{c}\text { parça } \\
\text { numune }\end{array}$ & 1 adet \\
\hline \multirow{13}{*}{$\begin{array}{l}\text { Fiziko } \\
\text { Mekanik } \\
\text { Özellikler }\end{array}$} & $\begin{array}{l}\text { Özgül ağırlık } \\
\text { tayini }\end{array}$ & ham & $\begin{array}{c}\text { parça } \\
\text { numune }\end{array}$ & 1 adet \\
\hline & $\begin{array}{l}\text { Görünür } \\
\text { yoğunluk tayini }\end{array}$ & \multirow{3}{*}{ ham } & \multirow{3}{*}{$5 \times 5 \times 5$} & \multirow{3}{*}{6 adet } \\
\hline & $\begin{array}{l}\text { Açlk gözeneklilik } \\
\text { tayini }\end{array}$ & & & \\
\hline & $\begin{array}{l}\text { Toplam yoğunluk } \\
\text { tayini }\end{array}$ & & & \\
\hline & $\begin{array}{l}\text { Atmosfer } \\
\text { basincinda su } \\
\text { emme tayini }\end{array}$ & ham & $5 \times 5 \times 5$ & 6 adet \\
\hline & $\begin{array}{l}\text { Ses hızı } \\
\text { ilerlemesi tayini }\end{array}$ & ham & $30 \times 7,5 \times 5$ & 6 adet \\
\hline & $\begin{array}{l}\text { Knoop sertliği } \\
\text { tayini }\end{array}$ & cilalı & $10 \times 7 \times 1$ & 6 adet \\
\hline & $\begin{array}{l}\text { Shore sertliği } \\
\text { tayini }\end{array}$ & ham & $30 \times 5 \times 5$ & 6 adet \\
\hline & $\begin{array}{l}\text { Tek eksenli } \\
\text { basınç tayini }\end{array}$ & ham & $5 \times 5 \times 5$ & 10 adet \\
\hline & $\begin{array}{l}\text { Sabit moment } \\
\text { altında eğilme } \\
\text { tayini }\end{array}$ & ham & $30 \times 5 \times 5$ & 10 adet \\
\hline & $\begin{array}{l}\text { Nokta yük } \\
\text { dayanım indeksi }\end{array}$ & ham & $5 \times 5 \times 5$ & 10 adet \\
\hline & $\begin{array}{l}\text { Darbe dayanımı } \\
\text { tayini }\end{array}$ & ham & $4 \times 4 \times 4$ & 6 adet \\
\hline & $\begin{array}{l}\text { Don tesirine } \\
\text { dayanıklılık } \\
\text { tayini }\end{array}$ & ham & $5 \times 5 \times 5$ & 10 adet \\
\hline
\end{tabular}

Mineralojik-petrografik analizler kapsamında; Maden Tetkik ve Arama Genel Müdürlügü (MTA) MineralojiPetrografi Laboratuar'ında doğal taş örneklerinin ince kesitleri hazırlatılmış ve hem MTA'da bulunan, hem de ESOGÜ'de bulunan optik mikroskoplar yardımıyla örneklerin mineralojik-petrografik özellikleri belirlenmiştir. Örneklerin minör ve majör element tayini Afyon Kocatepe Üniversitesi (AKÜ) Akredite Doğal Taş Analiz Laboratuarı (DAL)'nda TS EN 15309 kodlu X Işını Floresans Yöntemi kullanılarak elementel bileşimin tayini isimli standarda göre, X-Işınları Floresans Spektrometresi (XRF) cihazı ile gerçekleştirilmiștir. Fiziko-mekanik özelliklerden; özgül ağırlık, görünür ve toplam yoğunluk, açık gözeneklilik, atmosfer basıncında su emme, ses hızı ilerlemesi, Knoop sertliği, Shore sertliği, tek eksenli basınç, sabit moment altında eğilme, nokta yük dayanım indeksi ve don tesirine dayanıklılık tayini deneyleri AKÜ DAL'da ve darbe dayanımı deneyi ise, MTA Teknolojik Araştırmalar Doğal Taş Analiz Laboratuarı'nda gerçekleştirilmiştir.

\subsection{Kopma Enerjisi ve Çarpma Dayanımı Tayini Deneyi}

TS EN 14158 kodlu, 'Doğal taşlar - Deney Yöntemleri Kopma Enerjisinin Tayini' isimli standart kullanılarak Kemalpaşa Beyaz (K), Muğla Beyaz (M), Afyon Şeker (A) ticari isimli mermerlerin kopma enerjisinin belirlenmesi ve standartta var olmayan bir hesaplama yöntemi ile mermerlerin çarpma dayanımlarının hesaplanması hedeflenmiştir. Çalışmada, farklı numune kalınlıkları kullanılarak mermerlerin kopma enerjisi ve çarpma dayanımı üzerinde numune kalınlığının etkisinin ortaya konması amaçlanmıştır. Bunun için, TS EN 14158 kodlu standarttaki 20x20x3 cm boyutlu numunelere ek olarak, 20x20x2 cm ve 20x20x1 cm boyutlu cilalı numuneler kullanılmıştır. Her bir kalınlık ve her bir örnek için 1'er adet kontrol ve 5'er adet deney numunesi olmak üzere toplamda 9 adet kontrol numunesi ve 54 adet deney numunesi kullanılmıştır (Tablo 2). Deneylerde, önce kontrol numuneleri kırılarak bu numunelerin kırılma yüksekliklerinden deney numunelerinin ilk bilye düşme yüksekliği hesaplanmaktadır.

Tablo 2

Kopma Enerjisi ve Çarpma Dayanımı Deneyi Numune Özellikleri

\begin{tabular}{|c|c|c|c|}
\hline $\begin{array}{l}\text { Örnek } \\
\text { Kodu }\end{array}$ & Ticari Adı & Boyut $(\mathrm{cm})$ & Numune Sayısı \\
\hline \multirow{5}{*}{ K } & \multirow{5}{*}{$\begin{array}{l}\text { Kemalpaşa } \\
\text { Beyaz }\end{array}$} & \multirow{2}{*}{$20 \times 20 \times 3$} & 1 kontrol numunesi \\
\hline & & & 5 deney numunesi \\
\hline & & \multirow{2}{*}{$20 \times 20 \times 2$} & 1 kontrol numunesi \\
\hline & & & 5 deney numunesi \\
\hline & & $20 \times 20 \times 1$ & $\begin{array}{l}1 \text { kontrol numunesi } \\
5 \text { deney numunesi }\end{array}$ \\
\hline \multirow{4}{*}{$\mathrm{M}$} & \multirow{4}{*}{ Muğla Beyaz } & \multirow{2}{*}{$20 \times 20 \times 3$} & 1 kontrol numunesi \\
\hline & & & 5 deney numunesi \\
\hline & & $20 \times 20 \times 2$ & 1 kontrol numunesi \\
\hline & & $20 \times 20 \times 1$ & 1 kontrol numunesi \\
\hline \multirow{4}{*}{ A } & \multirow{4}{*}{ Afyon Şeker } & $20 \times 20 \times 3$ & $\begin{array}{l}1 \text { kontrol numunesi } \\
5 \text { deney numunesi }\end{array}$ \\
\hline & & \multirow{2}{*}{$20 \times 20 \times 2$} & 1 kontrol numunesi \\
\hline & & & 5 deney numunesi \\
\hline & & $20 \times 20 \times 1$ & $\begin{array}{l}1 \text { kontrol numunesi } \\
5 \text { deney numunesi }\end{array}$ \\
\hline
\end{tabular}


Kopma enerjisinin belirlenebilmesi için ilgili standartta belirtilen özellikler ve çizimden (Şekil 2-a) yola çlkılarak; özel üretim bir cihaz geliştirilmiştir (Şekil 2b). Şekil 2-a'daki şematik gösterimde 1 ile gösterilen kum haznesi, 2 ile gösterilen çelik bilye, 3 ile gösterilen cetvel, 4 ile gösterilen bilye tutucu mıknatıs, 5 ile gösterilen ise numunedir. Özel olarak üretilen bu cihaz; numunelerin yerleștirildiği 40x40×15 cm boyutlarında bir kum haznesi, üzerinde düșey yönde hareket ettirilebilen ve deneyde kullanılan çelik bilyenin mıknatıs yardımıyla tutturulabildiği kayar şasiye sahip 1,5 m uzunluğunda bir metal sütun ve kayar şasinin düşey yönde hareketinin ve bilyenin düşüşünün dijital olarak kontrol edilebildiği bir kontrol paneli olmak üzere toplamda üç ana parçadan oluşmaktadır (Şekil 2b).

TS EN 14158 standardında tariflendiği gibi, cihazda numuneyi yerleștirmek için bulunan kum haznesine 2 $\mathrm{mm}-0,076 \mathrm{~mm}$ arasında tane büyüklügüne sahip kum konarak, $100 \mathrm{~mm}$ kalınlı̆̆ında bir silika kum yatağ oluşturulmuş ve numuneler bu kum yatağının üzerine cihazın merkezlenme aparatı yardımı ile merkezlenerek yerleștirilmiştir. Standartta belirtilmemiş olmasına rağmen; yapılan araştırmalar sonucunda, hazneye yerleştirilmek için tariflenen kum için en uygun kumun EN 196-1'e uygun maksimum agrega boyutu $2 \mathrm{~mm}$ olan Rilem Cembureau standart kumu olduğu tespit edilmiş ve Limak Batı Çimento San. ve Tic. A.Ş. Trakya Çimento Fabrikasında üretilen Standart Cen Kumu olarak da bilinen bu kum deneylerde kullanılmıștır. Ayrıca, TS EN 14158 kodlu standarda bu kumun özelliklerinin eklenmesi bundan sonra bu standart kullanılarak deney yapacak diğer araştırmacılar için deney prosedüründe standardizasyonu sağlayacağından, bu yöntem kullanılarak yapılacak farklı bilimsel çalışmalarda deney sonuçlarının karşılaştııılması ve yorumlanması açısından kolaylık ve doğruluk sağlayacaktır.

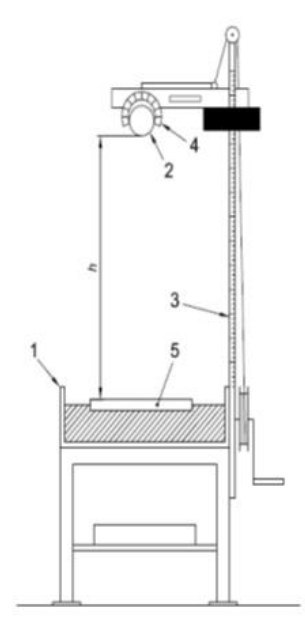

a

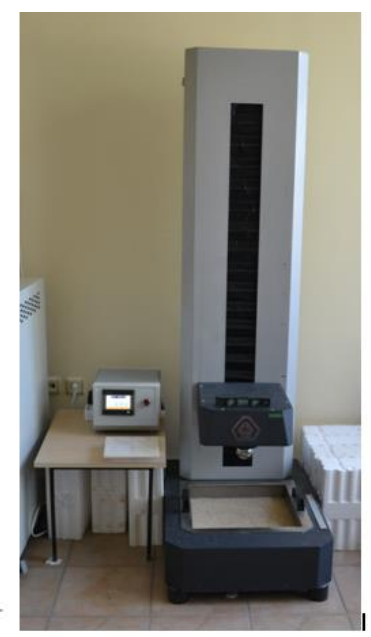

b
Şekil 2. Kopma Enerjisi Deney Cihazı; a) Şematik Görünümü; b) Yaptırılan Deney Cihazı
TS EN 14158 standardında kullanılan kum ile ilgili detaylı bir bilgi olmadığı gibi; deneyde kullanılacak çelik bilye ile ilgili de ağırlığı dışında başka hiç bir bilgi bulunmamaktadır. Standarda göre, deneylerde 1,0 0 0,01 kg kütleye sahip çelik bilye kullanılmalıdır. Ancak pek çok bilye üretici firmadan temin edilen kataloglar incelendiğinde standartta belirtilen ağırlıkta bir çelik bilye bulunamamış ve temin edilen çelik bilyeler tornalanarak standartta istenen ağırlı̆̆ getirildiğinde ise küreselliğinde bozulmalar olduğu tespit edilmiştir. Bilye küreselliğinin bozulması deneyi olumsuz etkileyeceğinden çalışmadaki deneyler üretici firmadan temin edilen ve standarttaki ağırlığa en yakın değer olan $1,0427 \mathrm{~kg}$ ağırlıklı krom çelik bilye ile gerçekleştirilmiştir. Bunun yanı sıra, krom çelik bilyenin temini için üreticilerden temin edilerek incelenen kataloglarda, bilyeler için ağırlıktan daha öncelikli tanımlamanın bilye çapı üzerinden olduğu tespit edilmiştir. Bu sebeple, standartta küresel çelik bilye tanımlanırken; bilye ağırlığının yanı sıra, bilye çapının da verilmesi daha uygun bir yaklaşım olacaktır. Bunların yanı sıra, deney sistematiğinin oturtulması için gerçekleștirilen ön deneylerde, $2 \mathrm{~cm}$ ve $1 \mathrm{~cm}$ kalınlıklı numuneler ile yapılan deneylerinde, 1,0427 kg kütleli bilye kullanıldığında; $1 \mathrm{~cm}$ numunelerin ilk düșüște, 2 $\mathrm{cm}$ numunelerin ise, çoğunlukla ilk, bazen de ikinci düşüşte kırılma eğilimde olduğu gözlemlenmiştir. $\mathrm{Bu}$ durum için Standartta, ilk bilye darbesiyle numunenin kırılması halinde sonucun değerlendirme dıșı bırakılarak deneyin tekrarlanması gerektiği vurgulanmıștır. Bu durumda $1 \mathrm{~cm}$ ve $2 \mathrm{~cm}$ kalınlıklı numunelerden veri alınması imkansızlaşmıştır. $\mathrm{Bu}$ nedenle de, çalışmada kullanılan farklı kalınlıktaki numunelere kalınlıkları ile nispeten orantılı ağırlıkta bilyeler kullanılmıștır. Tablo 3'de deneylerde kullanılan numune kalınlıklarına göre bilye ağırlıkları ve bilyelerin bazı kritik fiziko-mekanik özellikleri verilmiştir. TS EN 14158 standardında çelik küresel bilyenin fizikomekanik özellikleri de bulunmamaktadır. Ancak deneylerde standardizasyonun sağlanabilmesi için kumun teknik detaylarının standarda eklenmesinin gerektiği gibi çelik bilye ile ilgili de teknik detayların da standarda eklenmesinin oldukça önemli olduğu düşünülmektedir. 
Tablo3

Bilye Ağılıkları ve Özellikleri

\begin{tabular}{ccl}
\hline $\begin{array}{c}\text { Numune } \\
\begin{array}{c}\text { Boyutları } \\
(\mathrm{cm})\end{array}\end{array}$ & $\begin{array}{c}\text { Bilyelerin } \\
\text { Ağılıkları } \\
(\mathrm{kg})\end{array}$ & Bilyelerin Fiziko-Mekanik Özellikleri \\
\hline $20 \times 20 \times 3$ & 1,0427 & $\begin{array}{l}\text { Özgül ağırlık }=7,83 \mathrm{kgf} / \mathrm{mm} \\
\text { Sikışma kuvveti }=207 \mathrm{kgf} / \mathrm{mm} \\
\text { Kritik çekme dayanımı }=228 \mathrm{kgf} / \mathrm{mm} \\
\text { Elastisite modülü }=20,748 \mathrm{kgf} / \mathrm{mm} \\
\text { Brinnel sertliği }=60 / 66 \mathrm{HRC}\end{array}$ \\
\hline $20 \times 20 \times 2$ & 0,6787 &
\end{tabular}

TS EN 14158 standardında deney yöntemi, belirlenmiş aralıklarda artan yüksekliklerden küresel çelik bir bilyenin numunenin merkezine, numune kırllana kadar, tekrarlı serbest düşürülmesi ile numunenin kopma enerjisinin tayin edilmesi üzerine kurulmuştur. Standarda göre deneyde, $20 \times 20 \times 3 \mathrm{~cm}$ ebatlı, yüzeyi cilalı 1 tanesi kontrol numunesi ve 5 tanesi deney numunesi olmak üzere, toplamda 6 tane numune kullanılması gerekmektedir. Kopma tayini deneyine başlanmadan önce, $70 \pm 5{ }^{\circ} \mathrm{C}$ sıcaklıktaki etüvde $24 \pm 2$ saat süreyle kurutulan numuneler, oda sicaklığına gelene kadar desikatörde bekletilir ve sonra tartımları alınarak kaydedilir. Numuneler sabit tartıma gelene kadar işlem tekrar edilerek sabit tartıma gelen numuneler ile kopma enerjisinin tayini deneyine başlanır. $\mathrm{Bu}$ çalışmada kullanılan numunelerin tamamı standarttaki bu prosedüre uygun şekilde sabit tartıma getirildikten sonra deneyler gerçekleştirilmiştir.

Deneylere başlanırken öncelikle kontrol numunelerinin deneyleri gerçekleştirilerek kontrol numunelerinden elde edilen yüksekliklere istinaden deney numunelerinin deneyleri gerçekleştirilmiştir. İlk olarak, 20x20x3 cm boyutlu numunelerin deneyleri için K kodlu mermerlerin kontrol numunesi, numune yüzeyinin merkezi bilyenin merkezinden geçen dik doğru üzerinde konumlandırılacak şekilde haznedeki kumun merkezine yerleştirilerek, numune yarısına kadar kuma gömülmüş ve su terazisi ile numunenin yatay düzlemle paralelliği kontrol edilmiștir. Sonrasında, 1,0427 kg kütleli küresel çelik bilye (bilyenin en düşük noktası baz alınarak) $10 \mathrm{~cm}$ yükseklikten kumun üzerindeki kontrol numunesinin merkezine düşürülmüş ve numune kırılana kadar çelik bilyenin düşürülme yüksekliği her defasında 5'er cm yükseltilerek bilye numunenin merkezindeki aynı noktaya numune kırılan kadar düşürülmeye devam edilmiştir. Kontrol numunesinin kırıldığı yükseklik $\left(\mathrm{h}_{\mathrm{t}}\right.$ ) kaydedilmiş ve bu yöntemle M ve A kodlu örneklerin de kontrol numuneleri kırılarak, Denklem (1) yardımıyla, deney numunelerinin ilk düşme yükseklikleri $\left(h_{i}\right)$ standartta verildiği gibi hesaplanmıştır. $\mathrm{h}_{\mathrm{i}}=\mathrm{h}_{\mathrm{t}}-150$

$h_{i}$ : Deney numunelerinin ilk bilye düşme yüksekliği (cm)

$h_{t}$ : Kontrol numunesinin kırıldı̆̆ son bilye düşme yüksekliği $(\mathrm{cm})$

Yapılan deney sonuçlarının karşılaştırılmasının ve yorumlanmasının sağlanabilmesi için, aynı kalınlıklı farklı tüm mermer örneklere aynı deney prosedürünün uygulanması sağlanmış ve $\mathrm{K}, \mathrm{M}$, A kodlu kontrol numunelerinin (her kalınlık için 1'er tane olmak üzere toplamda 3 tane kontrol numunesi) son kırılma yüksekliklerinden en düşük olan değerler kullanılarak deney numunelerinin ilk bilye düşme yükseklikleri belirlenmiştir. Bu işlemler, 20x20x2 cm ve 20x20x1 cm boyutlu kontrol numuneleri için de gerçekleştirilmiş ve tüm numune boyutları için kontrol numunelerinin kırıldığı son bilye düşme yükseklikleri Tablo 4'de verilmiştir. Eşitlik (1) ve Tablo 4'deki değerler dikkate alındığında tüm deney numunelerin ilk bilye düşme yüksekliği $25 \mathrm{~cm}$ olarak belirlenmiştir.

Tablo 4

Kontrol Numunelerinin Son Kırılma Yüksekliği

\begin{tabular}{ccc}
\hline $\begin{array}{c}\text { Örnek } \\
\text { Kodu }\end{array}$ & $\begin{array}{c}\text { Numune Boyutu } \\
(\mathrm{cm})\end{array}$ & $\begin{array}{c}\text { Kirılma Yüksekliği } \\
(\mathrm{cm})\end{array}$ \\
\hline $\mathrm{K}$ & & 60 \\
$\mathrm{M}$ & $20 \times 20 \times 3$ & 55 \\
$\mathrm{~A}$ & & 40 \\
\hline $\mathrm{K}$ & & 60 \\
$\mathrm{M}$ & $20 \times 20 \times 2$ & 45 \\
$\mathrm{~A}$ & & 40 \\
\hline $\mathrm{K}$ & & 70 \\
$\mathrm{M}$ & $20 \times 20 \times 1$ & 60 \\
$\mathrm{~A}$ & & 40 \\
\hline
\end{tabular}

Kontrol numuneleri için yapılan tüm deney prosedürleri, deney numuneleri için de aynı şekilde gerçekleştirilmiştir. Deney numuneleri için Eşitlik (1) ile hesaplanan ilk düşme yüksekliği $\left(\mathrm{h}_{\mathrm{i}}\right) 25 \mathrm{~cm}$ kullanılarak, deney numunelerinin kırıldıkları ana kadar kontrol numunesinde olduğu gibi her defasında 5'er cm bilye düşürme yüksekliği arttırılarak deneyler yapılmıș ve her numune için kırılma yükseklikleri kaydedilerek, numunelerin kopma enerjileri Denklem (2), çarpma dayanımları ise Denklem (3) kullanılarak hesaplanmiştır.

$$
\mathrm{W}=\mathrm{m} \times \mathrm{g} \times \mathrm{h}_{\mathrm{t}}
$$

$\mathrm{W}$ : Kopma enerjisi (J)

m : Küresel çelik bilyenin kütlesi $(\mathrm{kg})$

g : Yerçekimi ivmesi $\left(9,806 \mathrm{~m} / \mathrm{s}^{2}\right)$

$\mathrm{h}_{\mathrm{t}}$ :Numune kırıldığı ana kadar bilye düşme yüksekliklerinin toplamı $\left(\mathrm{h}_{1}+\mathrm{h}_{2}+\ldots+\mathrm{h}_{\mathrm{n}}\right)(\mathrm{m})$ 


$$
\sigma_{\mathrm{c}}=\frac{\mathrm{W}}{\mathrm{V}}
$$

$\sigma_{c}:$ Çarpma dayanımı $(\mathrm{Pa})$

$\mathrm{V}:$ Numune hacmi $\left(\mathrm{m}^{3}\right)$

\subsection{Tanımlama Deney Sonuçları}

Çalışmada kullanılan mermerlerin kimyasal analiz sonuçları Tablo 5'te, mermerleri oluşturan ana ve tali bileşenlerin doku ve yapı özellikleri Tablo 6'da ve mermerlerin fiziko-mekanik analiz sonuçları Tablo 7'te verilmektedir.

\section{Bulgular ve Tartışma}

Tablo 5

Numunelerin Kimyasal Analiz Sonuçları

\begin{tabular}{|c|c|c|c|c|c|c|c|c|c|c|c|}
\hline & $\begin{array}{c}\mathrm{SiO}_{2} \\
(\%)\end{array}$ & $\begin{array}{r}\mathrm{Al}_{2} \mathrm{O}_{3} \\
(\%)\end{array}$ & $\begin{array}{r}\mathrm{Fe}_{2} \mathrm{O}_{3} \\
(\%)\end{array}$ & $\begin{array}{l}\mathrm{CaO} \\
(\%)\end{array}$ & $\begin{array}{r}\mathrm{MgO} \\
(\%)\end{array}$ & $\begin{array}{r}\mathrm{P}_{2} \mathrm{O}_{5} \\
(\%)\end{array}$ & $\begin{array}{l}\mathrm{K}_{2} \mathrm{O} \\
(\%)\end{array}$ & $\begin{array}{l}\mathrm{SO}_{3} \\
(\%)\end{array}$ & $\begin{array}{l}\text { SrO } \\
(\%)\end{array}$ & $\begin{array}{r}\text { Kuzdırma } \\
\text { Kaybı (\%) }\end{array}$ & $\begin{array}{r}\text { Toplam } \\
(\%)\end{array}$ \\
\hline K & 0,096 & 0,070 & 0,038 & 55,1 & 1,02 & 0,019 & 0,0089 & 0,0177 & 0,0143 & 43,6 & 99,98 \\
\hline M & 0,149 & 0,065 & 0,224 & 47,2 & 7,09 & 0,016 & 0,0287 & 0,0158 & 0,0159 & 45,2 & 100,00 \\
\hline A & 0,236 & 0,190 & 0,060 & 55,1 & 0,57 & 0,011 & 0,0329 & 0,0133 & 0,0124 & 43,8 & 100,03 \\
\hline
\end{tabular}

Tablo 6

Numuneleri Oluşturan Ana ve Tali Bileșenlerin Doku ve Yapı Özellikleri

\begin{tabular}{|c|c|c|c|}
\hline & $\mathrm{K}$ & $\mathrm{M}$ & $\mathrm{A}$ \\
\hline $\begin{array}{l}\text { Karbonat } \\
\text { Mineralleri }\end{array}$ & $\begin{array}{l}\text { küçük - orta - iri taneli } \\
\text { (mikro - mezo - makrokristalin) } \\
\text { ksenomorfik } \\
\text { genellikle izometrik bazen anizometrik şekilli } \\
\text { sinırları genellikle düzensiz ve süturlu (grift), } \\
\text { bazen basit ve düz } \\
\text { homojen dağlımlı } \\
\text { izotropik }\end{array}$ & $\begin{array}{l}\text { küçük - orta taneli } \\
\text { (mikro - mezokristalin) } \\
\text { genellikle ksenomorfik - hipidiyomorfik } \\
\text { genellikle izometrik şekilli } \\
\text { sinırları bazen basit ve düz, bazen düzensiz } \\
\text { ve süturlu (grift) } \\
\text { homojen dağlımlı } \\
\text { izotropik }\end{array}$ & $\begin{array}{l}\text { küçük taneli } \\
\text { (mikrokristalin) } \\
\text { ksenomorfik } \\
\text { genellikle izometrik şekilli } \\
\text { sınırları düzensiz ve süturlu } \\
\text { (grift) } \\
\text { homojen dağılımlı } \\
\text { izotropik }\end{array}$ \\
\hline $\begin{array}{l}\text { Kuvars } \\
\text { Mineralleri }\end{array}$ & $\begin{array}{l}\text { çok çok az / eser oranda } \\
\text { küçük taneli (mikrokristalin) } \\
\text { çoğunlukla ksenomorfik } \\
\text { izometrik şekilli } \\
\text { heterojen dağılımlı }\end{array}$ & $\begin{array}{l}\text { çok çok az / eser oranda } \\
\text { küçük taneli (mikrokristalin) } \\
\text { ksenomorfik } \\
\text { heterojen dağllımlı }\end{array}$ & $\begin{array}{l}\text { çok az oranda } \\
\text { küçük taneli (mikrokristalin) } \\
\text { çoğunlukla ksenomorfik } \\
\text { genellikle izometrik şekilli } \\
\text { heterojen dağılımlı }\end{array}$ \\
\hline $\begin{array}{l}\text { Mika } \\
\text { Mineralleri }\end{array}$ & $\begin{array}{l}\text { çok az oranda } \\
\text { küçük taneli (mikrokristalin) } \\
\text { çoğunlukla ksenomorfik } \\
\text { yapraksı - ince yapraksı şekilli } \\
\text { heterojen dağılımlı(belirli hat boyunca gelişim) }\end{array}$ & $\begin{array}{l}\text { çok çok az / eser oranda } \\
\text { küçük taneli (mikrokristalin) } \\
\text { ksenomorfik } \\
\text { heterojen dağılımlı }\end{array}$ & $\begin{array}{l}\text { çok az oranda } \\
\text { küçük taneli (mikrokristalin) } \\
\text { çoğunlukla ksenomorfik } \\
\text { şeritimsi-çok ince yapraksı şekilli } \\
\text { heterojen dağılımlı }\end{array}$ \\
\hline $\begin{array}{l}\text { Opak } \\
\text { Mineralleri }\end{array}$ & $\begin{array}{l}\text { çok çok az / eser oranda } \\
\text { küçük taneli (mikrokristalin) } \\
\text { ksenomorfik - hipidiyomorfik } \\
\text { izometrik şekilli } \\
\text { heterojen dağılımlı }\end{array}$ & $\begin{array}{l}\text { çok çok az / eser oranda } \\
\text { küçük taneli (kripto-mikrokristalin) } \\
\text { ksenomorfik } \\
\text { heterojen dağılımlı }\end{array}$ & $\begin{array}{l}\text { çok az oranda } \\
\text { küçük taneli (mikrokristalin) } \\
\text { hipidiyomorfik - idiyomorfik } \\
\text { izometrik şekilli } \\
\text { heterojen dağllımlı }\end{array}$ \\
\hline $\begin{array}{l}\text { Piroksen } \\
\text { Mineralleri }\end{array}$ & $\begin{array}{l}\text { çok az oranda } \\
\text { küçük taneli (mikro - mezokristalin) } \\
\text { çoğunlukla ksenomorfik } \\
\text { prizmatik şekilli } \\
\text { heterojen dağılımlı(belirli hat boyunca gelișim) }\end{array}$ & 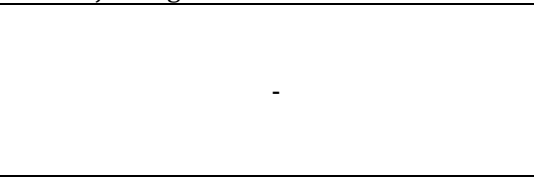 & ( \\
\hline
\end{tabular}


Tablo 7

Fiziko-Mekanik Analiz Sonuçları

\begin{tabular}{|c|c|c|c|c|c|c|}
\hline & \multicolumn{2}{|c|}{$\mathrm{K}$} & \multicolumn{2}{|c|}{$\mathrm{M}$} & \multicolumn{2}{|c|}{ A } \\
\hline & Ortalama & $\begin{array}{r}\text { Standart } \\
\text { Sapma }\end{array}$ & Ortalama & $\begin{array}{r}\text { Standart } \\
\text { Sapma }\end{array}$ & Ortalama & $\begin{array}{r}\text { Standart } \\
\text { Sapma }\end{array}$ \\
\hline Özgül Ağırlık (g/cm³) & 2,74 & 0,003 & 2,77 & 0,004 & 2,77 & 0,004 \\
\hline Gerçek Yoğunluk $\left(\mathrm{g} / \mathrm{cm}^{3}\right)$ & 2,65 & 0,001 & 2,68 & 0,003 & 2,66 & 0,002 \\
\hline Açık Gözeneklilik (\%) & 0,46 & 0,075 & 0,32 & 0,036 & 0,24 & 0,057 \\
\hline Toplam Gözeneklilik (\%) & 3,12 & 0,058 & 3,20 & 0,123 & 2,68 & 0,074 \\
\hline Atmosfer Basıncında Su Emme (\%) & 0,19 & 0,011 & 0,12 & 0,013 & 0,12 & 0,000 \\
\hline Ses Hızı (m/s) & 5388,80 & 94,672 & 5952,40 & 50,208 & 6265,00 & 33,541 \\
\hline Darbe Dayanımı (MPa) & 83,20 & 16,888 & 59,20 & 7,155 & 110,00 & 0,000 \\
\hline Tek Eksenli Basınç Dayanımı (MPa) & 78,20 & 4,324 & 140,40 & 1,140 & 110,20 & 0,837 \\
\hline Nokta Yük Dayanım İndeksi (MPa) & 1,98 & 0,085 & 3,74 & 0,169 & 3,54 & 0,156 \\
\hline Sabit Moment Altında Eğilme Dayanımı (MPa) & 10,57 & 1,097 & 13,40 & 0,344 & 9,42 & 0,519 \\
\hline Don Sonrası Basınç Dayanımı (MPa) & 65,00 & 3,162 & 116,40 & 12,857 & 107,20 & 7,463 \\
\hline Shore Sertliği (HS) & 49,56 & 0,590 & 54,74 & 0,581 & 51,98 & 0,536 \\
\hline Knoop Sertliği (HK) & 137,60 & 0,548 & 136,00 & 1,000 & 135,60 & 1,342 \\
\hline
\end{tabular}

Tablo 5'te verilen kimyasal analiz sonuçlarına göre üç mermerin de yüksek oranda $\mathrm{CaO}$ içerdiği ve bu oranının $\mathrm{K}$ ve $\mathrm{A}$ mermeri için \%55,1, M mermeri için \%47,2 olduğu görülmektedir. Bunun yanı sıra; M mermeri \%7,09 ile diğer iki mermere kıyasla daha fazla oranda MgO içermektedir.

$\mathrm{K}, \mathrm{M}$ ve $\mathrm{A}$ mermerlerinin el numuneleri makroskobik olarak incelendiğinde, $\mathrm{K}$ mermerinin gözle görülen iri kristallere sahip en heterojen tane boyu dağılımı gösteren örnek olduğu; M mermerinin $\mathrm{K}$ mermerinden daha homojen tane boyu yapılı ve $\mathrm{K}$ mermerinden daha küçük ama A mermerine göre de daha büyük tane boyuna sahip minerallerden oluştuğu; A mermerinin ise, en ince ve homojen tane boyuna sahip olduğu gözlemlenmiştir. Tablo 6 incelendiğinde, her üç mermerinde ana bileşeni olan karbonat minerallerinde; K mermerinde mikro-mezo-makrokristalin yapının, M mermerinde mikro-mezokristalin yapının, A mermerinde ise mikrokristalin yapının gözlemlendiği ifadeleri de mermerlerin el numunelerinde gözle gözlemlenen tane boyu dağılımı ve tane boyu yapısını mikroskobik olarak da desteklemektedir. K mermeri için karbonat minerallerinde genellikle düzensiz ve süturlu (grift) bazen de, basit ve düz bir durumda birbirleri ile kenetlenmesi sonucunda mermer dokusu (granoblastik ve heteroblastik doku) oluşmuştur. M mermeri için karbonat minerallerinde sınır ilișkilerinin ve kayacın dokusal bütünlüğünün (granoblastik dokusu) çok büyük ölçüde bozulduğu ve A mermeri için karbonat minerallerinin grift bir şekilde birbirleri ile kenetlenmesi sonucunda mermer dokusu (granoblastik doku) yerleștiği tespit edilmiştir. Ayrıca K mermerinde metamorfizma sırasında, köken kayaçta bulunan kristallerin sıcaklık ve basınç gibi metamorfik etmenlerle çözünmeden, daha ideal ve iyi gelişmiş olarak yeniden kristallenmesi olayı olan, rekristalizasyonun geliştiği gözlemlenmiştir. M mermerinde ise, ikincil süreçlere bağlı olarak, yaygınca, rekristalizasyonun ve metamorfizma öncesi kayaçta mevcut olmayan yeni minerallerin oluşumunu kapsayan süreç ya da yeni mineral oluşumu anlamına gelen neomineralizasyonun geliştiği gözlemlenmiştir. A mermerinin ana bileșeni olan karbonat minerallerinde, rekristalizasyon ve basınç etkisiyle kayacı oluşturan minerallerde gelişen ezilme, parçalanma, deformasyon anlamına gelen kataklaz gelişmiștir. Bunun yanı sıra; $\mathrm{K}$ ve $M$ mermerinde olmayan süreksizlikler, A mermerinde tespit edilmiștir. $\mathrm{Bu}$ süreksizlikler, ince/çok ince genişlikte, değişik uzunluklarda, düzensiz gelişmiş, heterojen dağılımlı, stilolit özelliğinde olduğu, (başlıca) sub-mikroskobik opak minerallerce ve (az orandaki) ince kristalli muskovit-serizit minerallerince dolguludur.

Mermerlerin Tablo 7'deki fiziko-mekanik özellikleri incelendiğinde; özgül ağırlık, görünür yoğunluk ve Knoop sertliği değerlerinin her üç mermer için oldukça yakın olduğu görülmektedir. En yüksek açık gözenekliliğe sahip K mermeri, aynı zamanda en yüksek su emme değerine de sahiptir. M ve A mermerlerinin su emme değerleri her ne kadar eşit olsa da; A mermerinin açık gözeneklilik değeri en düşüktür. Ses hızı değerleri, nispeten az gözenekli ve küçük mineral tane boyuna sahip A mermerinde en fazla ve içlerinde porozitesi en yüksek ve en büyük mineral tane boyuna sahip $\mathrm{K}$ mermerinde ise en azdır. Basınç dayanımı ve don sonrası basınç dayanımı en yüksek olan M mermeri iken; en düşük olan açık gözenekliliği de en yüksek olan $\mathrm{K}$ mermeridir. Nokta yük dayanım indeks değeri, MgO içeriği yüksek ve orta-ince mineral tane boyuna sahip M mermeri ile ince mineral tane boyuna sahip A mermerinde hemen hemen aynı ölçülmüştür. Mineral tane boyu diğer iki mermere göre daha iri ve mineral taneleri daha heterojen yapılı olan $\mathrm{K}$ mermerinde ise nokta yükü dayanım indeks değeri en düşüktür. Mineral tane boyu en küçük ve mineral taneleri homojen A mermerinin en düşük eğilme dayanımı değerine sahip 
olduğu görülmektedir. $\mathrm{Bu}$ durumun mikroskobik incelemede tespit edilen diğer iki mermerde hiç olmamasına karşın A mermerinde bulunan kataklaz dokusundan ve mikro düzeyde içerdiği süreksizliklerden kaynaklandığı düşünülmektedir.

\subsection{Kopma Enerjisi ve Çarpma Dayanımı Deney Sonuçları}

Tablo 8'de tüm numuneler için yapılan bilye düşürme deneylerinden elde edilen kopma enerjisi sonuçlarının minimum değerleri, maksimum değerleri, ortalamaları ve standart sapmaları verilmektedir.

Tablo 8

Kopma Enerjisi (J) Sonuçları

\begin{tabular}{|c|c|c|c|c|c|c|}
\hline & $\begin{array}{c}\text { Numune } \\
\text { Kalınlığ } \\
(\mathrm{cm})\end{array}$ & $\begin{array}{l}\text { Numune } \\
\text { Sayısı }\end{array}$ & Min. & Max. & Ort. & $\begin{array}{r}\text { Standart } \\
\text { Sapma }\end{array}$ \\
\hline \multirow{3}{*}{ K } & 1 & 5 & 12,76 & 17,33 & 15,47 & 1,9212 \\
\hline & 2 & 5 & 22,64 & 26,97 & 24,37 & 2,3716 \\
\hline & 3 & 5 & 41,43 & 56,26 & 48,69 & 5,2451 \\
\hline \multirow{3}{*}{ M } & 1 & 5 & 8,82 & 12,76 & 9,99 & 1,7534 \\
\hline & 2 & 5 & 11,65 & 22,64 & 17,31 & 4,1657 \\
\hline & 3 & 5 & 23,01 & 28,64 & 27,51 & 2,5178 \\
\hline \multirow{3}{*}{ A } & 1 & 5 & 7,09 & 10,71 & 8,51 & 1,5054 \\
\hline & 2 & 5 & 11,65 & 14,98 & 12,98 & 1,8239 \\
\hline & 3 & 5 & 13,30 & 17,90 & 16,06 & 2,5195 \\
\hline
\end{tabular}

Numune kalınlığının hesaplamaya katılmadığı, sadece bilye ağırlığı ve toplam kırılma yüksekliği kullanılarak hesaplanan kopma enerjisi değerleri, aynı mermerin farklı kalınlıkları için, numune kalınlığı arttıkça artmaktadır. Diğer bir deyişle; numune kalınlığı arttıkça, numuneyi kırmak için gereken toplam enerji olan, kopma enerjisi değerleri de artmaktadır. K mermerinin $3 \mathrm{~cm}$ kalınlıklı numunelerini kırmak için ortalama 48,69 J enerjiye ihtiyaç varken; $2 \mathrm{~cm}$ kalınlıklı numunelerini kırmak için ortalama 24,37 J enerjiye ve $1 \mathrm{~cm}$ kalınlıklı numunelerini kırmak için ise, ortalama 15,47 J enerjiye ihtiyaç vardır. Ayrıca mermerlerin farklı türleri için yapılan deneylerde standart sapma değerleri incelendiğinde; en düşük standart sapma değerleri A mermerinin kopma enerjisi değerlerindedir. A mermerinin tekrarlı deney sonuçlarının birbirine yakın çıkmasının ince ve homojen mineral tane yapısından kaynaklandığı söylenebilir.

Çarpma dayanımı değerleri, kopma enerjisi değerlerinin numune hacmine bölünmesiyle hesaplanmıștır. Deneylerde kullanılan numunelerin piyasada döşeme ve kaplama malzemesi olarak kullanılan numunelerle aynı olabilmesi için, numuneler fabrikaların üretim hatlarından rassal bir şekilde, temin edilen levhalardan boyutlandırılmıştır. Her üç mermer de farklı fabrikalarda kesilerek boyutlandırıldığından, numunelerin hacimleri için genel bir kabul yapılmak yerine; deneylerde kullanılan tüm numunelerin kenar uzunlukları ve kalınlıkları tek tek ölçülmek suretiyle numunelerin hacimleri hesaplanmıştır.

Tüm numunelere ait bilye düşürme deneylerinden elde edilen çarpma dayanımı sonuçları Tablo 9'da verilmektedir.

Tablo 9

Çarpma Dayanımı (kPa) Sonuçları

\begin{tabular}{|c|c|c|c|c|c|c|}
\hline & $\begin{array}{c}\text { Numune } \\
\text { Kalınlığ } \\
(\mathrm{cm})\end{array}$ & $\begin{array}{c}\text { Numune } \\
\text { Sayısı }\end{array}$ & Min. & Max. & Ort. & $\begin{array}{l}\text { Standart } \\
\text { Sapma }\end{array}$ \\
\hline \multirow{3}{*}{ K } & 1 & 5 & 30,52 & 41,44 & 37,00 & 4,5920 \\
\hline & 2 & 5 & 28,49 & 33,94 & 30,67 & 2,9851 \\
\hline & 3 & 5 & 33,02 & 44,84 & 38,81 & 4,1804 \\
\hline \multirow{3}{*}{ M } & 1 & 5 & 21,73 & 31,43 & 24,60 & 4,3175 \\
\hline & 2 & 5 & 15,10 & 29,34 & 22,44 & 5,3989 \\
\hline & 3 & 5 & 19,55 & 24,32 & 23,37 & 2,1332 \\
\hline \multirow{3}{*}{ A } & 1 & 5 & 14,62 & 22,10 & 17,55 & 3,1112 \\
\hline & 2 & 5 & 15,18 & 19,52 & 16,92 & 2,3771 \\
\hline & 3 & 5 & 11,75 & 15,82 & 14,19 & 2,2292 \\
\hline
\end{tabular}

Numune kalınlıklarına göre çarpma dayanımı değerleri incelendiğinde; $\mathrm{K}$ mermerinin $1 \mathrm{~cm}$ kalınlıktaki numunelerinin çarpma dayanımı ortalama $37 \mathrm{kPa}, 2 \mathrm{~cm}$ kalınlıktakilerin ortalama $30,67 \mathrm{kPa}, 3 \mathrm{~cm}$ kalınlıktakilerin ise 38,81 kPa çıkmıştır. M mermerinin kalınlıktaki numunelerinin çarpma dayanımı ortalama $24,60 \mathrm{kPa}, 2 \mathrm{~cm}$ kalınlıktakilerin çarpma dayanımı ortalama 22,44 $\mathrm{kPa}, 3 \mathrm{~cm}$ kalınlıktakilerin 23,37 $\mathrm{kPa}$ çıkmıştır. A mermerinin farklı kalınlıklarındaki numunelerinde de durum, K ve M mermerlerine benzer şekildedir. Yani, çarpma dayanımı değerleri $1 \mathrm{~cm}$ kalınlıklı numunelerde daha yüksek çıkarken; $2 \mathrm{~cm}$ ve 3 cm kalınlıklı numunelerde daha düşük çıkmıştır. Çarpma dayanımı hesaplanırken, her taş türü için her kalınlıkta ortak bir hacim kullanılmayıp; her deney numunesi için hacim kalınlık ve kenar uzunlukları ölçülerek hesaplanmıştır. Aynı fabrikanın üretim hattından rassal alınan aynı tür, aynı boyutlu numunelerin bile hacim değerleri birbiri ile aynı değildir. Deneylerde kullanılan numunelerdeki bu değişimler genel olarak tanımlanacak olursa; aynı fabrikadan alınan mermerler için kenar uzunluğu ve kalınlık değerlerindeki değişimler \%2'yi; farklı fabrikalardan alınan mermerler için kenar uzunluğu değerlerindeki değişimler \%3'ü, $2 \mathrm{~cm}$ ve $3 \mathrm{~cm}$ kalınlıklı 
numunelerin kalınlık değerlerindeki değişimler \%6'yı, 1 $\mathrm{cm}$ kalınlıklı numunelerin kalınlık değerlerindeki değişimler \%12'yi bulmaktadır. Numunelerin temin edildiği fabrikaların üretim hattı çıkışındaki bu ebatlama salınımlarının hesaplamasında numune hacminin kullanıldığı çarpma dayanımı sonuçlarını da etkilediği düşünülmektedir.

Bilye düşürme cihazıyla kırılan numunelerden $1 \mathrm{~cm}$ kalınlıklı olanlar Şekil 3'de, 2 cm kalınlık olanlar Şekil 4'de ve $3 \mathrm{~cm}$ kalınlıklı olanlar ise Şekil 5'de verilmektedir.

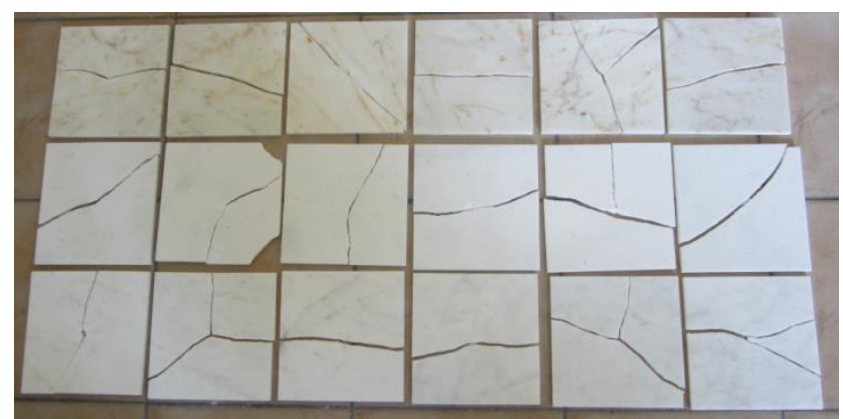

Şekil 3. $1 \mathrm{~cm}$ Kalınlıklı Numunelerin Deney Sonrası Kırılma Şekilleri

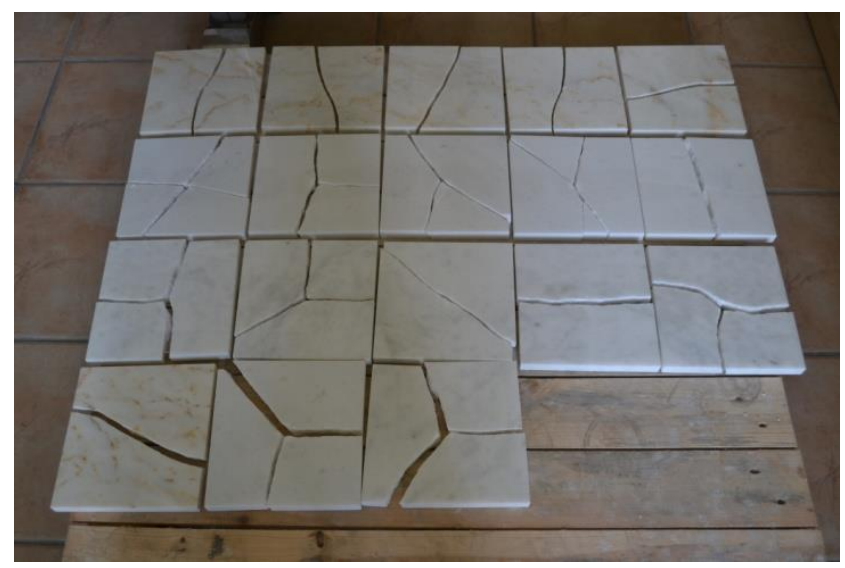

Șekil 4. 2cm Kalınlıklı Numunelerin Deney Sonrası Kırılma Şekilleri

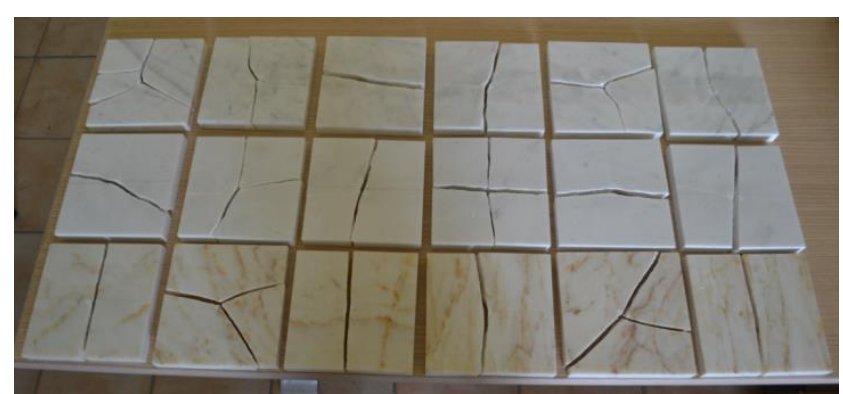

Şekil 5. $3 \mathrm{~cm}$ Kalınlıklı Numunelerin Deney Sonrası Kırılma Şekilleri

\section{Sonuçlar}

Çalışmada doğal taşların kopma ve çarpma dayanımının belirlenmesinde TS EN 14158 standardındaki deney prosedürüne bağlı kalınmıștır. Ancak; kopma enerjisi ve çarpma dayanımına numune kalınlığın etkisinin değerlendirilebilmesi için, numune boyutu olarak; $20 \times 20 \times 3 \mathrm{~cm}, 20 \times 20 \times 2 \mathrm{~cm}$ ve $20 \times 20 \times 1 \mathrm{~cm}$ boyutlu numuneler ve mineral tane boyunun etkisini değerlendirebilmek için ise ince, orta, iri mineral tane boyuna sahip Afyon Şeker (A), Muğla Beyaz (M) ve Kemalpaşa Beyaz (K) ticari isimli gerçek mermerler kullanılmıştır.

Kopma enerjisi, taşın kırılması için gereken toplam enerji miktarıdır. Çarpma dayanımı ise; bir taşın çarpma etkisiyle kırılmaya karşı gösterdiği dirençtir. Bir taşı kırmak için gereken enerji ne kadar fazla ise; taşın gösterdiği direnç de o kadar fazla olacaktır. Bu nedenle kopma enerjisi arttıkça, çarpma dayanımı da artmaktadır. Artan numune kalınlığıyla birlikte, kopma enerjisi artan mermerlerin çarpma dayanımı da artmaktadır. Kemalpașa Beyaz Mermeri en yüksek kopma enerjisi değerine sahip olduğu gibi, en yüksek çarpma dayanımı değerine de sahiptir. Aynı şekilde; Afyon Beyaz Mermeri en düşük kopma enerjisine sahip olduğu gibi, en düşük çarpma dayanımına da sahiptir.

Numune kalınlığına göre sonuçlar değerlendirildiğinde; en yüksek kopma enerjisi değerine sahip numuneler, 3 cm kalınlıklı numuneler; en düşük kopma enerjisi değerine sahip numuneler, $1 \mathrm{~cm}$ kalınlıklı numunelerdir. Numune kalınlığı arttıkça malzemeyi kırmak için gereken enerji olan kopma enerjisi değeri de artmaktadır.

Numune türüne göre sonuçlar değerlendirildiğinde; en yüksek kopma enerjisi ve çarpma dayanımı değerine sahip taşın Kemalpaşa Beyaz Mermeri; en düşük kopma enerjisi ve çarpma dayanımı değerine sahip taşın ise Afyon Şeker Mermeri olduğu tespit edilmiştir. Kullanılan mermerler içinde; Afyon Şeker Mermeri en homojen ve küçük mineral tane boyuna sahipken; Kemalpaşa Beyaz Mermeri, en heterojen boyutlu ve iri mineral tane boyuna sahip mermerdir. Bu çalışma için, mineral tane boyu ile dinamik bir yöntem ile belirlenen kopma enerjisi ve çarpma dayanımı değerleri arasında doğrusal bir ilișki tespit edildiği söylenebilir. Ancak mineral tane boyu ile kopma enerjisi ve çarpma dayanımı arasında doğrusal bir ilişki vardır şeklinde genel bir değerlendirmenin sadece bu çalıșmayla ortaya konabilmesi mümkün değildir. Bunun için farklı taş türleri ile çok sayıda deney gerçekleștirilmesi gerekmektedir. $\mathrm{Bu}$ tespitin kesinleştirilebilmesi için gelecekte çalışmanın daha fazla numune ile gerçekleştirilmesi planlanmaktadır.

TS EN 14158 Doğal tașların kopma enerjisinin tayini isimli standartta kullanılan bilye ve kumun özellikleri ile ilgili detaylı bilgiler bulunmamaktadır. Bu iki malzeme 
deneylerin gerçekleştirilmesinde son derece önemli olduğundan bunların daha detaylı olarak standarda eklenerek standart daha açlk hale getirilmelidir. Böylelikle standardın kullanımında kullanıcıdan kaynaklı değişiklikler minimuma indirilecek ve standart kullanılarak gerçekleştirilen çalışmaların sonuçları birbiri ile daha etkin mukayese edilebilecektir.

\section{Teşekkür}

$\mathrm{Bu}$ çalışma Eskişehir Osmangazi Üniversitesi Bilimsel Araştırma Projeleri Koordinasyon Birimi tarafindan 2015-762 nolu proje kapsamında desteklenmiştir.

\section{Araştırmacıların Katkısı}

$\mathrm{Bu}$ araştırmada; Ece KUNDAK, deneylerin yapılması, bilimsel yayın araștırması ve makalenin oluşturulması; Hürriyet AKDAŞ ve Gencay SARIIŞIK, makalenin gelişmesinde fikri katkının sağlanması, makale sonuçlarının değerlendirilmesi konularında katkı sağlamıştır.

\section{Çıkar Çatışması}

Yazarlar tarafından herhangi bir çıkar çatışması beyan edilmemiştir.

\section{Kaynaklar}

Koçu, N. ve Dereli, M. (2003). Mermerlerin günümüz mimarisinde kaplama (duvar-döşeme) elemanı olarak kullanılması ve uygulama sorunları, Türkiye 4. Mermer Sempozyumunda Sunulmuş Bildiri, Afyonkarahisar.

Kundak, E. (2016). Gerçek Mermerlerin Farklı Ortam Koşullarında Kopma Enerjisi ve Çarpma Dayanımının Belirlenmesi (Doktora Tezi). Eskișehir Osmangazi Üniversitesi Fen Bilimleri Enstitüsü, Eskişehir.

Onargan, T., Köse, H., ve Deliormanll, A.H. (2011). Mermer, Başak Matbaacılı. TMMOB Maden Mühendisleri Odası.

Öztank, N. ve Türkmen, F. (2001). Mermer-kireçtaşı ve konglomeraların yapılarda kullanımını denetleyen parametreler, Türkiye 3. Mermer Sempozyumunda Sunulmuş Bildiri, Afyonkarahisar.

Sarışık, G. (2012). Determining performance of marble finished products on their usage areas by a new impact-resistance test method, Journal of Testing and Evaluation, 40-5, 1-7. doi: https://doi.org/10.1520/JTE104352
Sarıșık, G., Kundak, E., Akdaş, H., ve Özkan, E. (2012). Mermer plakalarda çarpma dayanımı deneyi ve sınıflandırılması, 8. Mermer ve Doğal Taş Kongresinde Sunulmuş Bildiri, Afyonkarahisar.

Sarışık, G., Özkan, E., Kundak, E. \& Akdaş, H. (2016). Classification of parameters affecting impact resistance of natural stones, Journal of Testing and Evaluation, 44-4, 1650-1660. doi: https://doi.org/10.1520/JTE20140276

TS EN 14158, (2004). Doğal Taş Deney MetotlarıKopma Enerjisinin Tayini.

TS EN 15309, (2008). Atıkların ve toprağın nitelendirilmesi - X Işını Floresans Yöntemi Kullanılarak Elementel Bileşimin Tayini.

TS EN 196-1, (2016). Çimento Deney Metotları - Bölüm 1: Dayanım Tayini. 